\title{
The future of surgical lung biopsy: moving from the operating room to the bronchoscopy suite
}

\author{
Anny Godin ${ }^{1}$, Juan Carlos Molina ${ }^{1}$, Julie Morisset ${ }^{2}$, Moishe Liberman $^{1}$ \\ ${ }^{1}$ CETOC, CHUM Endoscopic Tracheo-bronchial and Oesophageal Center, Division of Thoracic Surgery, ${ }^{2}$ Division of Pulmonology, Department \\ of Medicine, University of Montreal, Montreal, Quebec, Canada \\ Contributions: (I) Conception and design: All authors; (II) Administrative support: M Liberman; (III) Provision of study materials or patients: All \\ authors; (IV) Collection and assembly of data: A Godin, JC Molina, M Liberman; (V) Data analysis and interpretation: All authors; (VI) Manuscript \\ writing: All authors; (VII) Final approval of manuscript: All authors. \\ Correspondence to: Moishe Liberman. CETOC, CHUM Endoscopic Tracheo-bronchial and Oesophageal Center, Division of Thoracic Surgery, \\ University of Montreal, Montreal, Quebec, Canada. Email: moishe.liberman@umontreal.ca.
}

\begin{abstract}
Assessment of patients with suspected interstitial lung disease includes a complete work-up consisting of history and physical examination, laboratory studies, lung function testing, high-resolution CT scan, bronchoscopy with bronchoalveolar lavage, and cardiology workup. Presently, definitive diagnosis of interstitial lung disease is even more important because of newly available therapeutics. The high risk/ benefit ratio perceived in the literature for surgical lung biopsy motivates research for new biopsy techniques that ideally would have the same or better diagnostic yield as surgical lung biopsy with less morbidity, mortality and cost. If endoscopic transbronchial lung cryobiopsy can be shown to be associated with a low morbidity rate and high accuracy, we may be able to obtain a definitive histological diagnosis in a great majority of interstitial lung disease cases and forego complex, inefficient and inaccurate methods of disease diagnosis. Several groups have published prospective and retrospective series on endoscopic transbronchial lung cryobiopsy for interstitial lung disease with promising results and diagnostic yields up to $83 \%$ (range, 74-91\%). The main complications associated with endoscopic transbronchial lung cryobiopsy are pneumothoraces and bleeding. The optimal techniques and specific settings for endoscopic transbronchial lung cryobiopsy is currently being investigated. In this paper, we present a review of the literature for endoscopic transbronchial lung cryobiopsy and future perspectives.
\end{abstract}

Keywords: Interstitial lung disease (ILD); cryobiopsy, endoscopic procedures

Received: 07 October 2019; Accepted: 04 November 2019; Published: 19 December 2019.

doi: $10.21037 /$ ccts.2019.11.03

View this article at: http://dx.doi.org/10.21037/ccts.2019.11.03

\section{Introduction}

Endoscopic transbronchial lung cryobiopsy (TBLC) is becoming an important diagnostic tool in the diagnostic algorithm of interstitial lung disease (ILD). The exact methodology for carrying out the endoscopic procedure, the standardization of the technique as well as the comparison to the gold standard, surgical lung biopsy (SLB), in ILD is currently under investigation. In this paper, we present a review of the literature for TBLC and future perspectives.

\section{ILD}

ILD is challenging to diagnose, due to the fact that many subtypes of ILD have overlapping clinical and radiological features. ILD is defined as lung disease characterized by varying patterns of inflammation and fibrosis that affect the alveolar structures, interstitium, small blood vessels and small airways. ILD represents a heterogeneous group of more than 200 different rare pulmonary disorders. The reported prevalence is between 17.3 and 80.9 per 100,000, 
Table 1 Investigations for interstitial lung disease (5-9)

\begin{tabular}{|c|c|}
\hline Investigations & Specific tests \\
\hline Examination & $\begin{array}{l}\text { Signs of pulmonary hypertension or right heart failure, signs of connective tissue diseases (e.g., Raynaud's } \\
\text { phenomenon), inflammatory arthritis }\end{array}$ \\
\hline Serology & FBC, ANCA, ANA, ENA, RF, anti-CCP, ds-DNA, ACE, NT-pro-BNP, myositis antibodies \\
\hline HRCT scan & $\begin{array}{l}\text { Reticular opacities in basal and peripheral distribution of lung, traction bronchiectasis, honeycombing in } \\
\text { subpleural location of lung, ground glass opacities }\end{array}$ \\
\hline \multirow[t]{4}{*}{ Lung tissue specimens } & Bronchoalveolar lavage (BAL) \\
\hline & Endoscopic transbronchial forceps biopsy (TBB) \\
\hline & Video-assisted thoracoscopic surgery (VATS) biopsy \\
\hline & Thoracotomy biopsy \\
\hline
\end{tabular}

ILD, interstitial lung disease; FBC, full blood count; ANCA, anti-neutrophil cytoplasmic antibody; ANA, antinuclear antibodies; ENA, extractable nuclear antigen; RF, rheumatoid factor; CCP, cyclic citrullinated; ds-DNA, double-stranded DNA; ACE, angiotensin-converting enzyme; NT-pro-BNP, N-terminal pro-brain natriuretic peptide; DLCO, diffusion lung capacity for carbon monoxide.

and incidence between 3.6 and 31.5 per 100,000/year (1-4). The different histologic patterns have been associated with diverse clinical scenarios, with a wide variety of possible diagnoses and substantial implications on treatment options and prognosis $(5,6)$.

Presently, the diagnostic gold standard for ILD is both a multidisciplinary discussion (MDD) with the real-time integration of clinical, radiological and pathological data by experts in ILD. Biopsy is considered a last step, however, often a necessary one, in the complex diagnostic algorithm of ILD. When performed as a diagnostic tool, a lung biopsy with histologic analysis can impact the management of ILD for the treatment and the prognosis in more than three quarters of cases $(2,3)$.

\section{Investigations for ILD}

The identification of the specific types of ILD does not rely on a single test. It conversely relies on several clinical parameters and the clinical judgment of experts. Assessment of patients with suspected ILD includes a complete work-up consisting of history and physical examination, laboratory studies, lung function testing, high-resolution CT scan, bronchoscopy with bronchoalveolar lavage
(BAL), and cardiology workup (5-8) (Table 1). Data from studies correlating radiological and histological features has allowed to identify and characterize, in combination with clinical judgment, a significant proportion of patients with ILD. For instance, a typical usual interstitial pneumonia pattern on a high-resolution CT scan, in a compatible clinical context, is sufficient to establish the diagnosis of idiopathic pulmonary fibrosis (IPF) $(7,8)$, with a specificity of $94-100 \%(10-12)$ and a sensitivity of $48-73 \%(10-12)$. However, only about $50 \%$ of patients with IPF present with this radiologic pattern, and many cases present with clinical contexts that cannot exclude alternative diagnoses (13). In these specific cases, a histological evaluation is indicated to reach a definitive diagnosis. In ILD other than IPF, radiological intra-observer agreement is often poor, consequently diagnosis is difficult even with MDD (14). Nowadays, definitive diagnosis of ILD is even more important because of the newly available therapeutics, i.e., pirfenidone or nintedanib, that change the prognosis of the disease in appropriately diagnosed patients (13).

Parenchymal lung tissue sampled to investigate ILD can be obtained through various strategies including BAL, endoscopic transbronchial forceps biopsy (TBB), CTguided transthoracic lung biopsy (CT-TLB), SLB and more 
recently, TBLC.

$\mathrm{TBB}$ is not recommended as a standard test in the diagnostic algorithm of ILD based on current guidelines $(7,15,16)$. The specimens obtained are often too small (1-3 mm) and contain artifacts, which limit the histological evaluation of specimens. In a recent trial from Pajares et al., histological diagnosis was obtained in only $34.1 \%$ of patients who had a TBB (17). The diagnostic yield of this technique was of $29.1 \%$ (17). Other published results reveal similar diagnostic yields with TBB $(18,19)$. The low diagnostic yield can be explained by the involvement of terminal and respiratory bronchioles in ILD that are not easily accessed with forceps. TBB therefore misrepresents the overall disease process in ILD.

CT-TLB for ILD is described by Padrao et al. in a retrospective study from Portugal of 169 patients (20). A definitive or probable diagnosis was made in $66.3 \%$ of cases (20). The most frequent diagnosis was organizing pneumonia in $36.2 \%$ of cases (20). The diagnostic yields associated with CT-TLB are based mainly on retrospective series. The diagnostic yields range from $20 \%$ to $66 \%$ (20). The major complications were pneumothorax $(17.8 \%)$, mild hemoptysis $(7.7 \%)$ and hemothorax (1.2\%). Mortality occurred in $0.59 \%$ of cases (20).

SLB is the current gold standard technique to obtain lung tissue specimens in suspected ILD $(15,16)$. The diagnostic yield is $95 \%$ ( $42 \%$ to $100 \%$ ) in a recently published meta-analysis $(15,16)$. Moreover, in $40 \%$ to $90 \%$ of SLB, the result of the histological analysis changes the treatment strategy. It is very relevant for disease patterns where larger tissue samples are required, such as IPF where there is geographical heterogeneity of disease (9). However, SLB is currently only used in $4 \%$ to $5 \%$ of suspected ILD because of the associated significant complications (21). The reported rate of major postoperative complications is between $12.9 \%$ and $19.1 \%$ $(22,23)$. Major complications include prolonged air leak, pneumonia, acute exacerbation of underlying interstitial pneumonia, readmission and prolonged postoperative mechanical ventilation. The postoperative mortality for SLB in patients with ILD is between $1.8 \%$ and $3.6 \%$ for elective cases and increases to $16 \%$ in non-elective cases (16,22-26). We must remember that patients selected for SLB often have very poor lung function and have uncertain diagnosis after other investigations. These patients often have restrictive fibrotic lung parenchyma. These patients undergo general anesthesia with mechanical ventilation, one lung ventilation (OLV) in video-assisted thoracoscopic surgery (VATS). Chest tubes inserted during surgery can stay in place for several days and cause pain and splinting. A typical admission to the hospital for a minimum of 2 to 3 days for straightforward elective cases is required. Low risk patients including those younger than 65 years, with no significant comorbidity and preserved lung function are not initially considered for SLB $(21,27)$. The high risk/benefit ratio perceived in the literature for SLB motivates research for new biopsy techniques that ideally would have the same or better diagnostic yield as SLB with less morbidity, mortality and cost. As mentioned, less invasive methods used to diagnose ILD are of insufficient sensitivity $(7,15)$. If TBLC can be shown to be associated with a low morbidity rate and high accuracy, we may be able to obtain a definitive histological diagnosis in a great majority of ILD cases and forego complex, inefficient and inaccurate methods of disease diagnosis.

\section{History of cryobiopsy}

TBLC is a relatively new endoscopic technique used to obtain lung parenchyma specimens. It is a minimally invasive technique performed with a flexible or rigid bronchoscope under deep sedation or general anesthesia. Its use in ILD was first described by Babiak et al. in 2009 (28). A flexible cryoprobe was introduced into selected bronchi under fluoroscopic guidance in 41 patients and compared with TBB. The biopsy procedures were evaluated on specimen size, specimen quality and complications. Specimens from TBLC were of greater size and quality compared to TBB (mean specimen area $15.11 \mathrm{~mm}^{2}$ for TBCL vs. $5.82 \mathrm{~mm}^{2}$ for TBB). Two pneumothoraces were observed. According to Babiak, TBCL also contributed to definitive diagnosis in a substantial number of cases (28).

Cryoprobes exist since 1960. These probes are used as therapeutic tools for airway tumor debulking through multiple freeze-thaw cycles that cause cell death and necrosis. This technology is also used for cryoadhesion to remove tissue e.g., granulation or tumor from the airway. As the tissue rapidly freezes, it adheres to the probe and is avulsed. It is extracted with a quick pullback movement. The same principle applies to TBLC.

\section{Cryobiopsy principles}

The principle behind cryobiopsy using a cryoprobe is the Joule-Thomson effect. Compressed gas, most commonly carbon dioxide or nitrous oxide, is released at high flow 


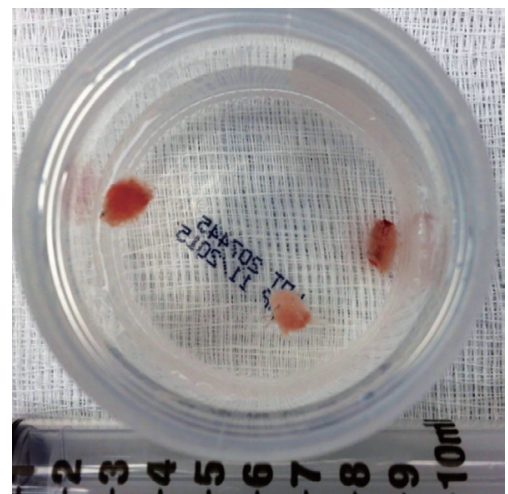

Figure 1 Endoscopic transbronchial lung biopsies.

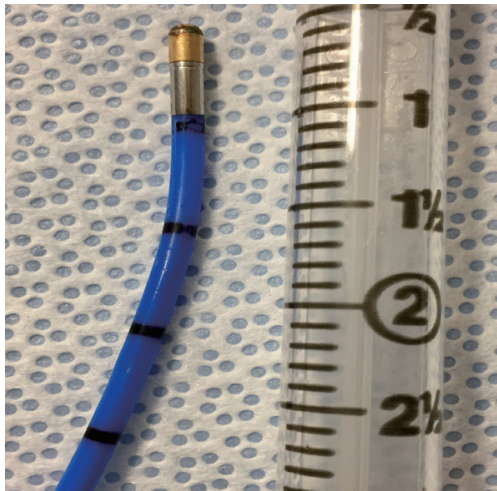

Figure 2 Flexible cryoprobe.

Table 2 Contraindications to endoscopic transbronchial lung cryobiopsy (based on expert opinion) $(31,32)$

Resting hypoxemia

Severe lung restriction on lung functions testing, i.e., FVC $<50 \%$ or oxygen diffusion issues, i.e., DLCO $<35 \%$ of predicted

High bleeding risk, i.e., bleeding diathesis, anticoagulant therapy in therapeutic dosage or thrombocytopenia (platelets $<50 \times 10^{9} / L$ )

Adverse reaction to general anesthesia

Pulmonary hypertension (systolic pulmonary artery pressure $>50 \mathrm{mmHg}$ )

Cervical instability (e.g., rheumatoid arthritis)

FVC, forced volume vital capacity; DLCO, diffusing capacity of the lung for carbon monoxide.

at the tip of the probe. The rapid gas expansion cools the tip of the probe to $-79^{\circ} \mathrm{C}$ when using carbon dioxide or $-89^{\circ} \mathrm{C}$ when using nitrous oxide, freezing the surrounding tissue $(28,29)$. As the tissue rapidly freezes, it adheres to the probe and is avulsed. It is extracted with a quick pullback movement (Figure 1).

Cryobiopsy is an endoscopic intervention and can be performed as an outpatient procedure. Presently, various techniques of TBLC for ILD have been described (28-30). Flexible cryoprobes of either 1.9 or $2.4 \mathrm{~mm}$ in diameter are used (Figure 2). Fluoroscopic guidance can also be used to determine the distance of the probe from the pleura and to confirm the location of the probe. In the literature, the freezing time is heterogeneous ( 5 to 8 seconds). Factors that can influence the freezing time are use of carbon dioxide or nitrous oxide, size of the probe, tissue properties and bronchus location i.e., lobar, segmental or subsegmental.

Based on expert opinion, contraindications to TBLC are based on bleeding risk and severity of hypoxemia (Table 2). Contraindications include resting hypoxemia, severe lung restriction on lung functions testing [i.e., forced vital capacity (FVC) $<50 \%$ ] or oxygen diffusion issues [i.e., diffusing capacity of the lung for carbon monoxide (DLCO) $<35 \%$ of predicted], high bleeding risk [i.e., bleeding diathesis, anticoagulant therapy in therapeutic dosage or thrombocytopenia (platelets $<50 \times 10^{9} / \mathrm{L}$ )], adverse reaction to general anesthesia, pulmonary hypertension (systolic pulmonary artery pressure $>50 \mathrm{mmHg}$ ) and cervical instability as in rheumatoid arthritis $(31,32)$. None of these recommended contraindications are based on evidence.

To prevent hemorrhagic complications, a Fogarty catheter or endobronchial balloon occlusion catheter can be used. The balloon catheter is used as a hemostatic bronchial balloon. The balloon is prophylactically placed near and proximal to the site of cryobiopsy in case of bleeding. The balloon can be prophylactically inflated immediately following each cryobiopsy attempt.

\section{Review of published lung cryobiopsy studies (main study characteristics and outcomes)}

As an emerging diagnostic technique for ILD, TBLC is a promising alternative to SLB as described in a recent metaanalysis published by Sethi et al. that included 31 studies 
and 1,443 patients (33). The enthusiasm for TBLC has led to an increase in lung biopsy in patients with ILD without specific diagnosis. The enthusiasm has led to two recent expert opinion papers published on the subject in 2018 and 2019 (31,32). Tables 3-5 present a summary of studies on endoscopic TBLC. Case series, meta-analysis and animal studies are analyzed.

Several groups have published prospective and retrospective series on TBLC for ILD with promising results and diagnostic yields up to $83 \%$ (range, $74-91 \%)(24,25,30,39-41)$. However, because this is an emerging technique, there is no standard way to perform TBLC, and the technical aspects for performing TBLC are heterogeneous among published series (23$25,30,41,52,57,58)$.

The main complications associated with TBLC are pneumothoraces and bleeding. The meta-analysis published by Sethi et al. reports an overall complication rate of $23.1 \%$, with a pooled incidence of pneumothorax of $9.4 \%$ and a significant bleeding rate of $14.2 \%$ (33). These results are similar to the results described previously by other authors $(24,51,52,57)$. Pneumothoraces are the consequence of a biopsy obtained too close to the visceral pleura, causing a disruption in its continuity. Significant bleeding is alleged to be caused by a biopsy taken in more proximal areas of the lung, where blood vessels are larger and the tract to the main airway is shorter (38). The size of the sample might also play a role in the development of these complications. Some authors have hypothesized that with longer freezing times, larger samples are obtained, with the downside being the increased risk of severe bleeding (53). There is very limited data on the influence of different technical components for performing TBLC, and definition of the optimal settings to obtain the best quality samples with the lowest incidence of complications are in need of scientific investigation.

Ravaglia et al. recently published an observational, retrospective cohort study on 699 patients with the use of TBLC in ILD (30). A definitive diagnosis was obtained with histologic analysis in $87.8 \%$ of cases (30). With the integration of MDD, diagnosis was obtained in $90.1 \%$ of cases (30). The diagnostic yield was significantly influenced by the number of samples taken $(1$ vs. 2 or more) $(\mathrm{P}<0.005)$ and the different locations of samples taken for fibrotic lung diseases $(\mathrm{P}<0.001)$. The complication rate was $19.2 \%$ for pneumothorax, $7.6 \%$ for moderate hemorrhage and $0.7 \%$ for severe hemorrhage (30). Factors that significantly influenced the risk of pneumothorax were the different locations of samples taken, location of samples in lower lobes, the use of $2.4 \mathrm{~mm}$ probe and a high radiologic fibrotic score (30). Radiologic fibrotic score evaluates the distribution of reticular abnormalities, the presence of traction bronchiectasis and honeycombing. Mortality occurred in $0.4 \%$ ( 3 patients) of cases within 30 days of TBLC. Risk of bleeding was increased in samples taken in lower lobes $(\mathrm{P}=0.027)$. For this study, Ravaglia presented strategies, in order to optimize the TBLC technique (Table 6) (30).

\section{Advantages and disadvantages of TBLC}

There are multiple advantages to TBLC that make it an interesting diagnostic technique for ILD (Table 7). This explains the increase in its popularity in some centers.

\section{Studies on standardization of endoscopic TBLC technique and comparison with SLB}

There exists a need for a standardized technique for performing TBLC to optimize quality of specimens and prevent complications. Studies evaluating technical aspects of TBLC and comparing TBLC to SBL are presently taking place.

Molina and Liberman presented the first phase of their study on technical aspects of TBLC at the Second Conference of the American Association for Bronchoscopy and Interventional Pulmonology in 2019. The study defines the optimal settings for TBLC using an ex-vivo porcine model by assessing the influence of different technical parameters on specimen quality and size. The technical parameters analyzed were probe size, freezing time and distance from the probe to pleura. One-hundred and thirtytwo biopsies were taken in an ex-vivo porcine lung model after 181 attempts from 5 sets of lungs. They systematically evaluated different parameters using $1.9-$ and $2.4-\mathrm{mm}$ probes, 3, 5, 8, 10, 15 and 20 seconds of freezing time and distances from pleura to the tip of the probe of 5,10 and $20 \mathrm{~mm}$. On Multivariate regression analysis including all samples and settings, there was a strong association between freezing time and sample weight and area. The main outcome was that freezing time is the main determinant of sample size for cryobiopsy in an ex-vivo porcine lung model, while probe size and distance from the tip of the probe to pleura had no significant influence. The second phase, presently underway, consists of analyzing in a canine model, the quality of specimens obtained by TBLC and the associated complications based on different protocols 


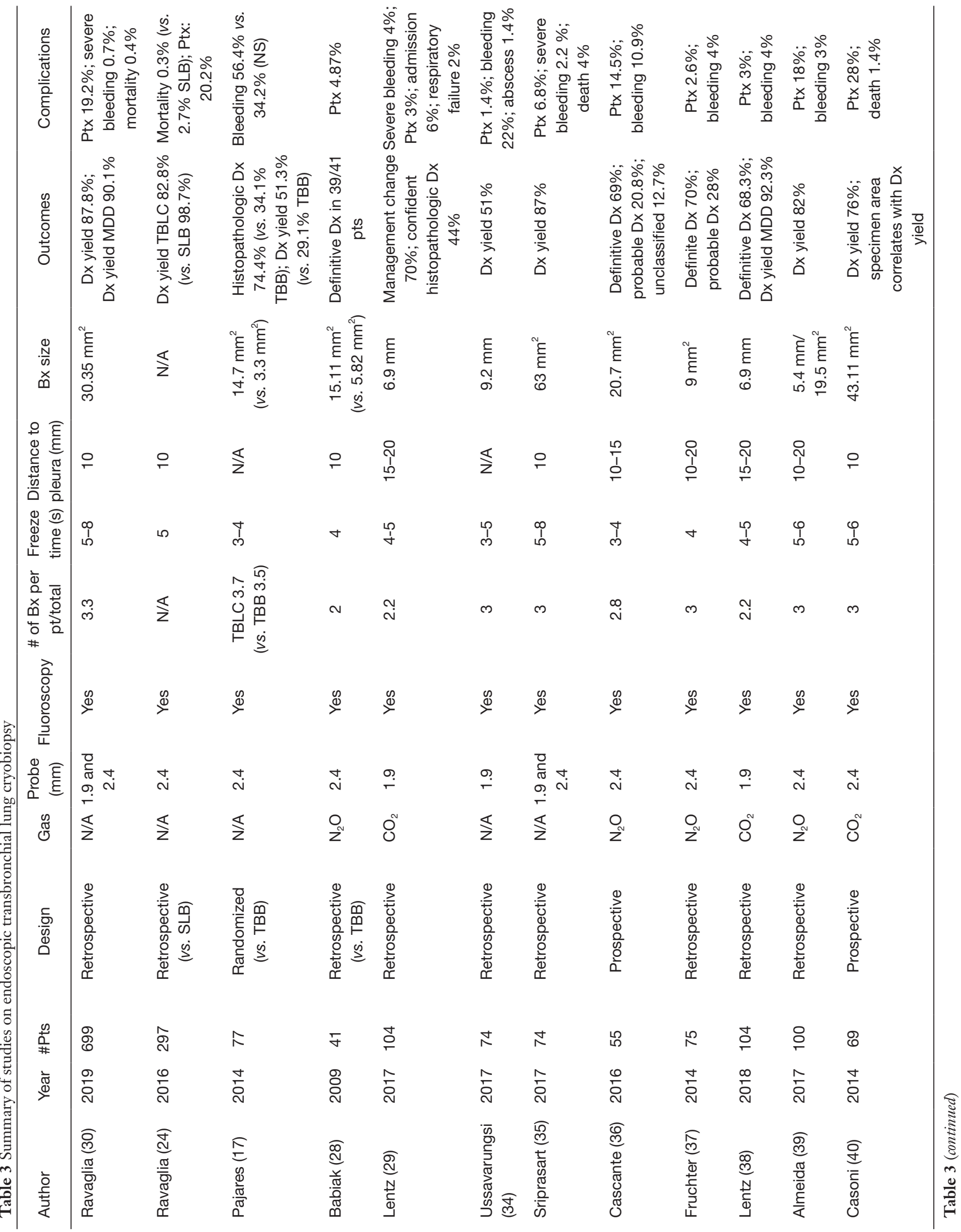




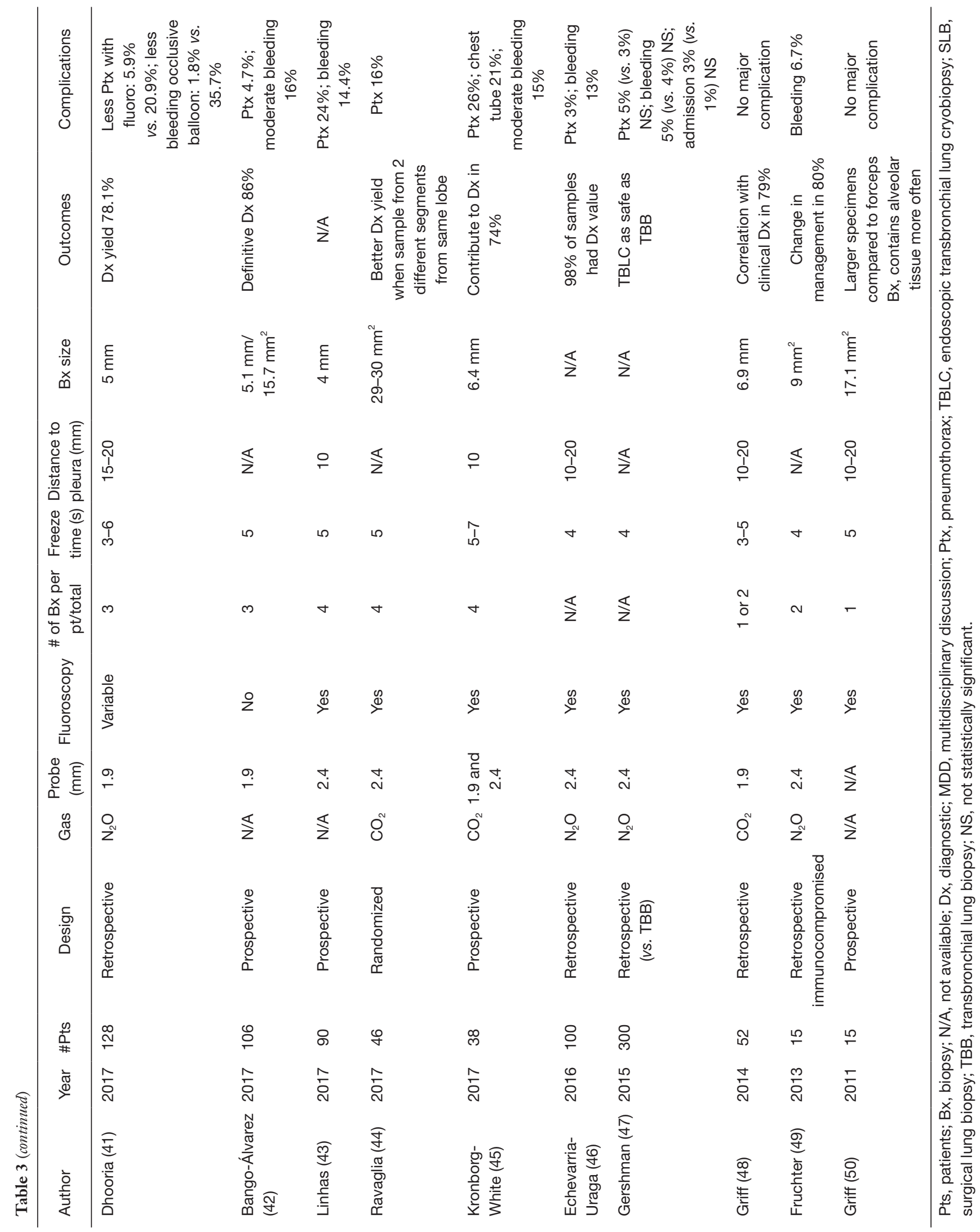


Table 4 Meta-analysis of endoscopic transbronchial lung cryobiopsy

\begin{tabular}{|c|c|c|c|c|c|}
\hline Author & Year & \# Pts in total & Bx size & Outcomes & Complications \\
\hline Iftikhar (25) & 2017 & $\begin{array}{l}642 \text { (TBLC) } \\
+1,549(\mathrm{SLB})\end{array}$ & N/A & $\begin{array}{l}\text { Dx yield: } 83.7 \% \text { (vs. } 92.7 \% \text { SLB); sensitivity: } 87 \% \\
\text { (vs. } 91 \% \text { SLB); specificity: } 57 \% \text { (vs. } 58 \% \text { SLB) }\end{array}$ & $\begin{array}{l}\text { Ptx } 9.5 \% \text {; moderate/severe } \\
\text { bleeding } 4.9 \%\end{array}$ \\
\hline Dhooria (51) & 2016 & 805 & $20.4 \mathrm{~mm}^{2}$ & $\begin{array}{l}\text { Dx yield (definitive Dx) } 76.9 \% \text { and (definitive + } \\
\text { probable) } 85.9 \% \text {; less artifact with TBLC }\end{array}$ & $\begin{array}{l}\text { Ptx } 6.8 \% \text {; severe bleeding } \\
0.3 \% \text {; death } 0.1 \%\end{array}$ \\
\hline Johannson (52) & 2016 & 731 & $\mathrm{~N} / \mathrm{A}$ & $\begin{array}{l}\text { Dx yield } 74-98 \%, 83 \% \text { pooled; Dx yield MDD } \\
51-98 \%, 79 \% \text { pooled }\end{array}$ & $\begin{array}{l}\text { Ptx } 12 \% \text {; moderate/severe } \\
\text { bleeding } 39 \%\end{array}$ \\
\hline
\end{tabular}

Pts, patients; Bx, biopsy; N/A, not available; Dx, diagnostic; Ptx, pneumothorax; TBLC, endoscopic transbronchial lung cryobiopsy; SLB, surgical lung biopsy.

Table 5 Summary of animal studies of endoscopic transbronchial lung cryobiopsy

\begin{tabular}{|c|c|c|c|c|c|c|c|c|c|c|c|}
\hline Author & Year & \# Animals & Design & Gas & $\begin{array}{l}\text { Probe } \\
(\mathrm{mm})\end{array}$ & Fluoroscopy & $\begin{array}{l}\text { \# of Bx } \\
\text { per pt/ } \\
\text { total }\end{array}$ & $\begin{array}{l}\text { Freeze } \\
\text { time (s) }\end{array}$ & $\begin{array}{l}\text { Distance } \\
\text { to pleura } \\
(\mathrm{mm})\end{array}$ & Bx size & Outcomes \\
\hline \multirow{2}{*}{$\operatorname{lng}(53)$} & \multirow{2}{*}{2016} & \multirow{2}{*}{2 sheep } & \multirow{2}{*}{$\begin{array}{l}\text { Animal } \\
\text { in vivo } \\
\text { (freeze } \\
\text { time vs. } \\
\text { size) }\end{array}$} & \multirow{2}{*}{$\mathrm{N} / \mathrm{A}$} & \multirow{2}{*}{1.9} & \multirow{2}{*}{ Yes } & \multirow{2}{*}{49 total } & \multirow{2}{*}{$1-6$} & \multirow{2}{*}{10} & \multirow{2}{*}{$\begin{array}{l}\text { Mean ranged } \\
\text { from } 4.7 \text { to } \\
15.3 \mathrm{~mm}^{2}\end{array}$} & $\begin{array}{l}1 \text { case of severe } \\
\text { hemorrhage ( } 6 \mathrm{~s} \\
\text { freezing time) }\end{array}$ \\
\hline & & & & & & & & & & & Ptx 3 \\
\hline $\begin{array}{l}\text { Franke } \\
(54)\end{array}$ & 2016 & 2 pigs & $\begin{array}{l}\text { Animal } \\
\text { ex-vivo } \\
\text { cryo (vs } \\
\text { TBB) }\end{array}$ & $\mathrm{CO}_{2}$ & 1.1 & $\mathrm{~N} / \mathrm{A}$ & 42 total & $2-6$ & 10 & $\begin{array}{l}8.08 \mathrm{~mm}^{2} \text { (vs. } \\
\left.2.61 \mathrm{~mm}^{2}\right)\end{array}$ & $\begin{array}{l}\text { Less artifact and more } \\
\text { alveolar tissue with cryo } \\
\text { Specimen weight } \\
\text { increase with activation } \\
\text { time }\end{array}$ \\
\hline $\begin{array}{l}\text { Franke } \\
(55)\end{array}$ & 2010 & 3 pigs & $\begin{array}{l}\text { Animal } \\
\text { in vivo } \\
\text { vs. TBB }\end{array}$ & $\mathrm{CO}_{2}$ & $\begin{array}{l}1.9 \text { and } I \\
2.4\end{array}$ & $N / A$ & 70 total & $1-3$ & $\mathrm{~N} / \mathrm{A}$ & $\begin{array}{l}\text { Depending on } \\
\text { probe size and } \\
\text { freeze time }\end{array}$ & $\begin{array}{l}\text { Diameter of } \\
\text { cryobiopsies was at } \\
\text { least } 30 \% \text { larger than } \\
\text { that of forceps biopsies }\end{array}$ \\
\hline $\begin{array}{l}\text { Franke } \\
(56)\end{array}$ & 2009 & $\begin{array}{l}\text { Lung (porcine, } \\
\text { liver (bovine } \\
\text { and porcine), } \\
\text { gastric mucosa } \\
\text { (porcine) }\end{array}$ & $\begin{array}{l}\text { Animal } \\
\text { in vitro }\end{array}$ & $\mathrm{CO}_{2}$ & $\begin{array}{l}1.0 \\
1.2 \\
1.9,2.4\end{array}$ & $\mathrm{~N} / \mathrm{A}$ & $\begin{array}{l}10 \text { per } \\
\text { setting }\end{array}$ & $1-6$ & $\mathrm{~N} / \mathrm{A}$ & $\begin{array}{l}\text { Depending on } \\
\text { probe size and } \\
\text { freeze time }\end{array}$ & $\begin{array}{l}\text { Diameter increase with } \\
\text { freeze time, probe size, } \\
\text { and pressure on tissue }\end{array}$ \\
\hline
\end{tabular}

Bx, biopsy; Pt, patient; N/A, not available; Dx, diagnostic; Ptx, pneumothorax; TBB, transbronchial biopsy. 
Table 6 Strategies to optimize endoscopic transbronchial lung cryobiopsy technique suggested by Ravaglia $(20,30,31)$

\begin{tabular}{|c|c|}
\hline Categories & Strategies \\
\hline Probe size & $\begin{array}{l}\text { Utilize the } 1.9 \mathrm{~mm} \text { probe }(2.4 \mathrm{~mm} \text { probe may be associated with a significantly increasing the } \\
\text { diagnostic yield) }\end{array}$ \\
\hline Lung function reserve & $\begin{array}{l}\text { The risk of pneumothorax also increases in cases of impaired lung function (FVC }<50 \% \text { and DLCO } \\
<35 \% \text { ) and sampling } 2 \text { sites }\end{array}$ \\
\hline $\begin{array}{l}\text { Use of a hemostatic bronchial } \\
\text { balloon }\end{array}$ & $\begin{array}{l}\text { It is preferable to intubate the patients (either with rigid tracheoscope or flexible tube), always using } \\
\text { bronchial blockers or catheters }\end{array}$ \\
\hline
\end{tabular}

FVC, forced vital capacity; DLCO, diffusion lung capacity for carbon monoxide.

Table 7 Advantages and disadvantages of endoscopic transbronchial lung cryobiopsy

\begin{tabular}{l}
\hline Advantages \\
\hline Minimally invasive technique \\
Possibility to perform as outpatient procedure \\
Reproducible \\
Larger parenchyma size specimens than TBB \\
High quality specimens, similar to SLB \\
Diagnostic yield similar to SLB (under investigation) \\
Fewer complications than SLB \\
Less expensive than SLB \\
Ability to perform under deep sedation as opposed to general \\
anesthesia \\
Disadvantages \\
Non standardized technique \\
Very heterogeneous technical components among series \\
Major complications include pneumothorax and bleeding \\
No standardized protocol \\
Concerns that a lung tissue specimen is many-fold smaller in \\
and incorrect histopathological interpretation
\end{tabular}

SLB, surgical lung biopsy; TBB, transbronchial lung biopsy.

(probe size, freezing time and distance to pleura) to devise a standardized technique for TBLC.

The study COLDICE is presently recruiting patients in Australia to evaluate the agreement between TBLC and
SLB sampled concurrently from the same patients, for both histopathological and MDD diagnoses (9). The accuracy of TBLC will be assessed by agreement with VATS at both histopathological analysis and MDD diagnosis (9).

\section{Conclusions}

In conclusion, TBLC is an emerging technique with an interesting diagnostic yield of $83 \%$ for ILD. The yield may be improved with better techniques without compromising safety. Technique is probably not the only factor that influences the diagnostic yield for TBLC. Obtaining the biopsy in the most affected segment of the lung and the number of biopsies taken are also important factors. Future perspectives may be to evaluate performing TBLC under navigational bronchoscopy, radial endobronchial ultrasound or under direct guidance using real-time computed tomography.

\section{Acknowledgments}

Funding: None.

\section{Footnote}

Conflicts of Interest: All authors have completed the ICMJE uniform disclosure form (available at http:// dx.doi.org/10.21037/ccts.2019.11.03). ML serves as an unpaid editorial board member of Current Challenges in Thoracic Surgery from Mar 2019 to Mar 2021. JM reports personal fees from Hoffman-La Roche, personal fees from 
Boehringer Ingelheim, outside the submitted work. The authors have no other conflicts of interest to declare.

Ethical Statement: The authors are accountable for all aspects of the work in ensuring that questions related to the accuracy or integrity of any part of the work are appropriately investigated and resolved.

Open Access Statement: This is an Open Access article distributed in accordance with the Creative Commons Attribution-NonCommercial-NoDerivs 4.0 International License (CC BY-NC-ND 4.0), which permits the noncommercial replication and distribution of the article with the strict proviso that no changes or edits are made and the original work is properly cited (including links to both the formal publication through the relevant DOI and the license). See: https://creativecommons.org/licenses/by-nc-nd/4.0/.

\section{References}

1. Kreuter M, Herth FJ, Wacker M, et al. Exploring Clinical and Epidemiological Characteristics of Interstitial Lung Diseases: Rationale, Aims, and Design of a Nationwide Prospective Registry--The EXCITING-ILD Registry. Biomed Res Int 2015;2015:123876.

2. Karakatsani A, Papakosta D, Rapti A, et al. Epidemiology of interstitial lung diseases in Greece. Respir Med 2009;103:1122-9.

3. López-Campos JL, Rodríguez-Becerra E, Neumosur Task Group, et al. Incidence of interstitial lung diseases in the south of Spain 1998-2000: the RENIA study. Eur J Epidemiol 2004;19:155-61

4. Coultas DB, Zumwalt RE, Black WC, et al. The epidemiology of interstitial lung diseases. Am J Respir Crit Care Med 1994;150:967-72.

5. American Thoracic Society, European Respiratory Society. American Thoracic Society/European Respiratory Society International Multidisciplinary Consensus Classification of the Idiopathic Interstitial Pneumonias. This joint statement of the American Thoracic Society (ATS), and the European Respiratory Society (ERS) was adopted by the ATS board of directors, June 2001 and by the ERS Executive Committee, June 2001. Am J Respir Crit Care Med 2002;165:277-304.

6. Travis WD, Costabel U, Hansell DM, et al. An official American Thoracic Society/European Respiratory Society statement: Update of the international multidisciplinary classification of the idiopathic interstitial pneumonias. Am
J Respir Crit Care Med 2013;188:733-48.

7. Raghu G, Remy-Jardin M, Myers JL, et al. Diagnosis of Idiopathic Pulmonary Fibrosis. An Official ATS/ERS/JRS/ ALAT Clinical Practice Guideline. Am J Respir Crit Care Med 2018;198:e44-68.

8. Lynch DA, Sverzellati N, Travis WD, et al. Diagnostic criteria for idiopathic pulmonary fibrosis: a Fleischner Society White Paper. Lancet Respir Med 2018;6:138-53.

9. Troy LK, Grainge C, Corte T, et al. Cryobiopsy versus open lung biopsy in the diagnosis of interstitial lung disease (COLDICE): protocol of a multicentre study. BMJ Open Respir Res 2019;6:e000443.

10. Silva CI, Muller NL, Lynch DA, et al. Chronic hypersensitivity pneumonitis: differentiation from idiopathic pulmonary fibrosis and nonspecific interstitial pneumonia by using thin-section CT. Radiology 2008;246:288-97.

11. Hunninghake GW, Zimmerman MB, Schwartz DA, et al. Utility of a lung biopsy for the diagnosis of idiopathic pulmonary fibrosis. Am J Respir Crit Care Med 2001;164:193-6.

12. Raghu G, Mageto YN, Lockhart D, et al. The accuracy of the clinical diagnosis of new-onset idiopathic pulmonary fibrosis and other interstitial lung disease: A prospective study. Chest 1999;116:1168-74.

13. Raghu G, Wells AU, Nicholson AG, et al. Effect of Nintedanib in Subgroups of Idiopathic Pulmonary Fibrosis by Diagnostic Criteria. Am J Respir Crit Care Med 2017;195:78-85.

14. Walsh SLF, Wells AU, Desai SR, et al. Multicentre evaluation of multidisciplinary team meeting agreement on diagnosis in diffuse parenchymal lung disease: a casecohort study. Lancet Respir Med 2016;4:557-65.

15. Raghu G, Collard HR, Egan JJ, et al. An official ATS/ ERS/JRS/ALAT statement: idiopathic pulmonary fibrosis: evidence-based guidelines for diagnosis and management. Am J Respir Crit Care Med 2011;183:788-824.

16. Han Q, Luo Q, Xie JX, et al. Diagnostic yield and postoperative mortality associated with surgical lung biopsy for evaluation of interstitial lung diseases: A systematic review and meta-analysis. J Thorac Cardiovasc Surg 2015;149:1394-401.e1.

17. Pajares V, Puzo C, Castillo D, et al. Diagnostic yield of transbronchial cryobiopsy in interstitial lung disease: a randomized trial. Respirology 2014;19:900-6.

18. Sheth JS, Belperio JA, Fishbein MC, et al. Utility of Transbronchial vs Surgical Lung Biopsy in the Diagnosis of Suspected Fibrotic Interstitial Lung Disease. Chest 
2017;151:389-99.

19. Berbescu EA, Katzenstein AL, Snow JL, et al. Transbronchial biopsy in usual interstitial pneumonia. Chest 2006;129:1126-31.

20. Padrão E, Rodrigues M, Guimarães S, et al. Diagnostic Yield of Computed Tomography-Guided Transthoracic Lung Biopsy in Diffuse Lung Diseases. Respiration 2018;96:455-63.

21. Hutchinson JP, McKeever TM, Fogarty AW, et al. Surgical lung biopsy for the diagnosis of interstitial lung disease in England: 1997-2008. Eur Respir J 2016;48:1453-61.

22. Kreider ME, Hansen-Flaschen J, Ahmad NN, et al. Complications of video-assisted thoracoscopic lung biopsy in patients with interstitial lung disease. Ann Thorac Surg 2007;83:1140-4.

23. Sharp C, McCabe M, Adamali H, et al. Use of transbronchial cryobiopsy in the diagnosis of interstitial lung disease-a systematic review and cost analysis. QJM 2017;110:207-14.

24. Ravaglia C, Bonifazi M, Wells AU, et al. Safety and Diagnostic Yield of Transbronchial Lung Cryobiopsy in Diffuse Parenchymal Lung Diseases: A Comparative Study versus Video-Assisted Thoracoscopic Lung Biopsy and a Systematic Review of the Literature. Respiration 2016;91:215-27.

25. Iftikhar IH, Alghothani L, Sardi A, et al. Transbronchial Lung Cryobiopsy and Video-assisted Thoracoscopic Lung Biopsy in the Diagnosis of Diffuse Parenchymal Lung Disease. A Meta-analysis of Diagnostic Test Accuracy. Ann Am Thorac Soc 2017;14:1197-211.

26. Hutchinson JP, Fogarty AW, McKeever TM, et al. InHospital Mortality after Surgical Lung Biopsy for Interstitial Lung Disease in the United States. 2000 to 2011. Am J Respir Crit Care Med 2016;193:1161-7.

27. Cottin V. Lung biopsy in interstitial lung disease: balancing the risk of surgery and diagnostic uncertainty. Eur Respir J 2016;48:1274-7.

28. Babiak A, Hetzel J, Krishna G, et al. Transbronchial cryobiopsy: a new tool for lung biopsies. Respiration 2009;78:203-8.

29. Lentz RJ, Argento AC, Colby TV, et al. Transbronchial cryobiopsy for diffuse parenchymal lung disease: a state-ofthe-art review of procedural techniques, current evidence, and future challenges. J Thorac Dis 2017;9:2186-203.

30. Ravaglia C, Wells AU, Tomassetti S, et al. Diagnostic yield and risk/benefit analysis of trans-bronchial lung cryobiopsy in diffuse parenchymal lung diseases: a large cohort of 699 patients. BMC Pulm Med 2019;19:16.
31. Colella S, Haentschel M, Shah P, et al. Transbronchial Lung Cryobiopsy in Interstitial Lung Diseases: Best Practice. Respiration 2018;95:383-91.

32. Poletti V, Ravaglia C, Dubini A, et al. How might transbronchial cryobiopsy improve diagnosis and treatment of diffuse parenchymal lung disease patients? Expert Rev Respir Med 2017;11:913-7.

33. Sethi J, Ali MS, Mohananey D, et al. Are Transbronchial Cryobiopsies Ready for Prime Time?: A Systematic Review and Meta-Analysis. J Bronchology Interv Pulmonol 2019;26:22-32.

34. Ussavarungsi K, Kern RM, Roden AC, et al. Transbronchial Cryobiopsy in Diffuse Parenchymal Lung Disease: Retrospective Analysis of 74 Cases. Chest 2017;151:400-8.

35. Sriprasart T, Aragaki A, Baughman R, et al. A Single US Center Experience of Transbronchial Lung Cryobiopsy for Diagnosing Interstitial Lung Disease With a 2-Scope Technique. J Bronchology Interv Pulmonol 2017;24:131-5.

36. Cascante JA, Cebollero P, Herrero S, et al. Transbronchial Cryobiopsy in Interstitial Lung Disease: Are We on the Right Path? J Bronchology Interv Pulmonol 2016;23:204-9.

37. Fruchter O, Fridel L, El Raouf BA, et al. Histological diagnosis of interstitial lung diseases by cryotransbronchial biopsy. Respirology 2014;19:683-8.

38. Lentz RJ, Taylor TM, Kropski JA, et al. Utility of Flexible Bronchoscopic Cryobiopsy for Diagnosis of Diffuse Parenchymal Lung Diseases. J Bronchology Interv Pulmonol 2018;25:88-96.

39. Almeida LM, Lima B, Mota PC, et al. Learning curve for transbronchial lung cryobiopsy in diffuse lung disease. Rev Port Pneumol (2006). 2017. [Epub ahead of print].

40. Casoni GL, Tomassetti S, Cavazza A, et al. Transbronchial lung cryobiopsy in the diagnosis of fibrotic interstitial lung diseases. PLoS One 2014;9:e86716.

41. Dhooria S, Mehta RM, Srinivasan A, et al. The safety and efficacy of different methods for obtaining transbronchial lung cryobiopsy in diffuse lung diseases. Clin Respir J 2018;12:1711-20.

42. Bango-Álvarez A, Ariza-Prota M, Torres-Rivas H, et al. Transbronchial cryobiopsy in interstitial lung disease: experience in 106 cases - how to do it. ERJ Open Res 2017. doi: 10.1183/23120541.00148-2016.

43. Linhas R, Marçôa R, Oliveira A, et al. Transbronchial lung cryobiopsy: Associated complications. Rev Port Pneumol (2006) 2017;23:331-7. 
44. Ravaglia C, Wells AU, Tomassetti S, et al. Transbronchial Lung Cryobiopsy in Diffuse Parenchymal Lung Disease: Comparison between Biopsy from 1 Segment and Biopsy from 2 Segments - Diagnostic Yield and Complications. Respiration 2017;93:285-92.

45. Kronborg-White S, Folkersen B, Rasmussen TR, et al. Introduction of cryobiopsies in the diagnostics of interstitial lung diseases - experiences in a referral center. Eur Clin Respir J 2017;4:1274099.

46. Echevarria-Uraga JJ, Perez-Izquierdo J, Garcia-Garai $\mathrm{N}$, et al. Usefulness of an angioplasty balloon as selective bronchial blockade device after transbronchial cryobiopsy. Respirology 2016;21:1094-9.

47. Gershman E, Fruchter O, Benjamin F, et al. Safety of Cryo-Transbronchial Biopsy in Diffuse Lung Diseases: Analysis of Three Hundred Cases. Respiration 2015;90:40-6.

48. Griff S, Schonfeld N, Ammenwerth W, et al. Diagnostic yield of transbronchial cryobiopsy in non-neoplastic lung disease: a retrospective case series. BMC Pulm Med 2014;14:171.

49. Fruchter O, Fridel L, Rosengarten D, et al. Transbronchial cryobiopsy in immunocompromised patients with pulmonary infiltrates: a pilot study. Lung 2013;191:619-24.

50. Griff S, Ammenwerth W, Schonfeld N, et al. Morphometrical analysis of transbronchial cryobiopsies. Diagn Pathol 2011;6:53.

51. Dhooria S, Sehgal IS, Aggarwal AN, et al. Diagnostic Yield and Safety of Cryoprobe Transbronchial Lung Biopsy in Diffuse Parenchymal Lung Diseases: Systematic Review

doi: $10.21037 /$ ccts.2019.11.03

Cite this article as: Godin A, Molina JC, Morisset J, Liberman M. The future of surgical lung biopsy: moving from the operating room to the bronchoscopy suite. Curr Chall Thorac Surg 2019;1:23. and Meta-Analysis. Respir Care 2016;61:700-12.

52. Johannson KA, Marcoux VS, Ronksley PE, et al. Diagnostic Yield and Complications of Transbronchial Lung Cryobiopsy for Interstitial Lung Disease. A Systematic Review and Metaanalysis. Ann Am Thorac Soc 2016;13:1828-38.

53. Ing M, Oliver RA, Oliver BG, et al. Evaluation of Transbronchial Lung Cryobiopsy Size and Freezing Time: A Prognostic Animal Study. Respiration 2016;92:34-9.

54. Franke KJ, Linzenbold W, Nuessle D, et al. A New Tool for Transbronchial Cryobiopsies in the Lung: An Experimental Feasibility ex vivo Study. Respiration 2016;91:228-34.

55. Franke KJ, Theegarten D, Hann von Weyhern C, et al. Prospective controlled animal study on biopsy sampling with new flexible cryoprobes versus forceps: evaluation of biopsy size, histological quality and bleeding risk. Respiration 2010;80:127-32.

56. Franke KJ, Szyrach M, Nilius G, et al. Experimental study on biopsy sampling using new flexible cryoprobes: influence of activation time, probe size, tissue consistency, and contact pressure of the probe on the size of the biopsy specimen. Lung 2009;187:253-9.

57. Ganganah O, Guo SL, Chiniah M, et al. Efficacy and safety of cryobiopsy versus forceps biopsy for interstitial lung diseases and lung tumours: A systematic review and meta-analysis. Respirology 2016;21:834-41.

58. Poletti V, Hetzel J. Transbronchial Cryobiopsy in Diffuse Parenchymal Lung Disease: Need for Procedural Standardization. Respiration 2015;90:275-8. 